\title{
Oral monophthong vowel qualities of the Jamee language in Aceh
}

\author{
Yunisrina Qismullah Yusuf*, Ika Apriani Fata, and Sinta Karwinda \\ Department of English Education, Faculty of Teacher Training and Education, \\ Universitas Syiah Kuala, Jalan T. Nyak Arief, Darussalam, Banda Aceh 23111, Indonesia
}

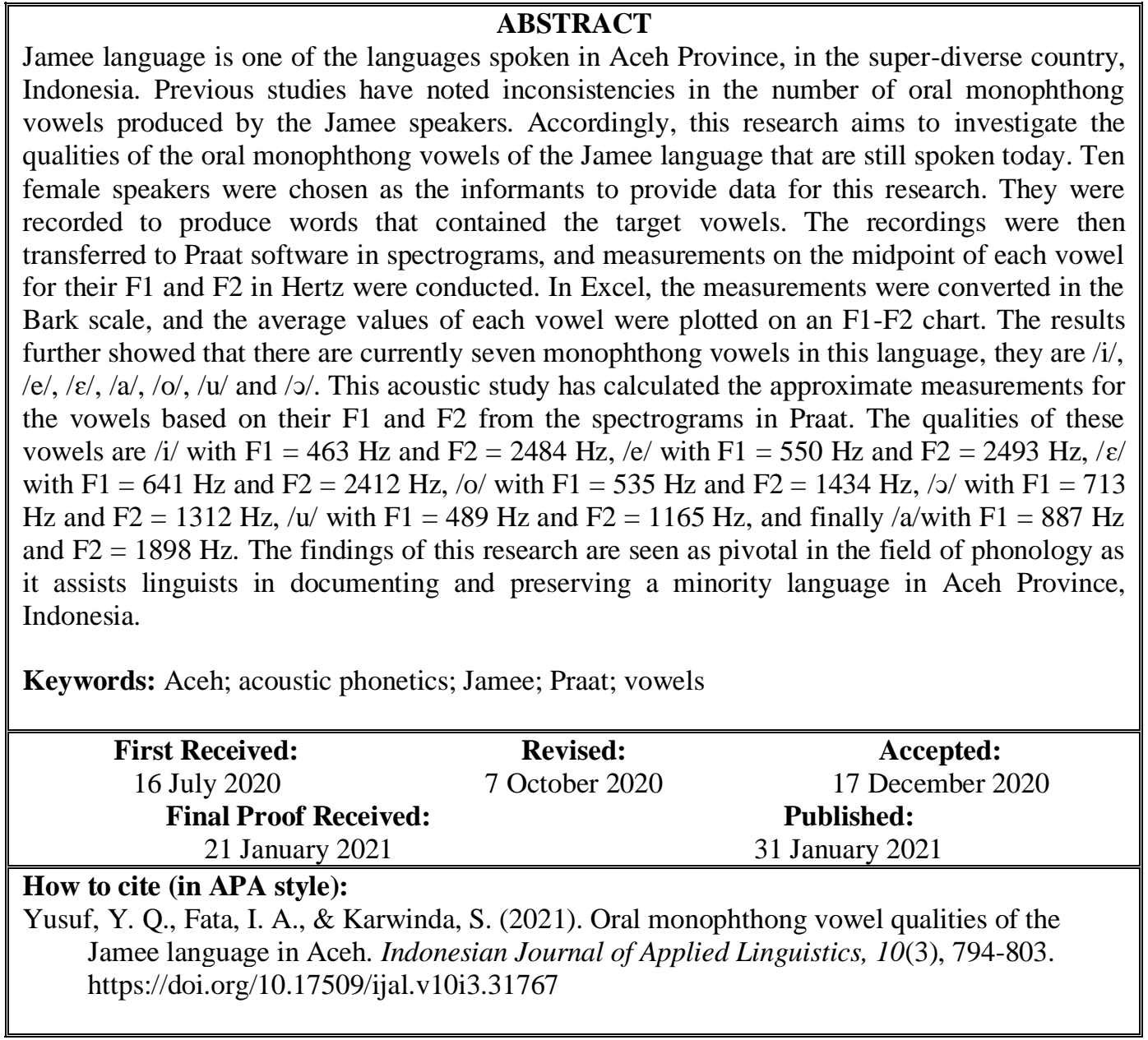

\section{INTRODUCTION}

Aceh is one of the provinces in Indonesia. Indonesian, as the national language, is used in formal settings throughout the country. In Aceh alone, nine languages are being spoken by the people in this province, and this is not to mention the various dialects and sub-dialects found within the main languages (Yusuf \& Pillai, 2012). In the South Aceh regency, there are about 77.000 people who speak the Jamee language (Abdullah et al., 1990). Among these speakers, about 25.000 people reside in Samadua and Tapaktuan, whilst 52.000 people reside in the other 14 districts of South Aceh, namely: Labuhan Haji, West Labuhan Haji, East Labuhan Haji, Meukek, Sawang, Pasie Raja, Central Kluet, South Kluet, East Kluet, North Kluet, East Bakongan, Bakogan, East Trumon, and Trumon. Nevertheless, Abdullah, et al. (1990) claim that the Jamee language spoken in these 14 districts is already blended with the Acehnese language. For the speakers in Tapaktuan, they are further influenced by the Indonesian language. Perhaps this 
is because Tapaktuan is the capital city of the South Aceh Regency, where the local government offices of the regency are located and the formal or national language of the country is used in administrations.

On the other hand, Abdullah et al. (1991) find Samadua speakers of the Jamee language have the least influence of other languages spoken in Aceh. They perceive that the language is still untainted compared to the Jamee language spoken by the speakers in the other districts. Moreover, even Indonesian is the national language to be spoken in this area, the Jamee language is also used in formal settings, where the teachers in school still do mostly insert this language in the formal teaching and learning processes. Additionally, teenagers also used Jamee among friends, as the media of conversations in coffee shops, in local government issues, and sale and purchase transactions in town.

In the previous studies conducted by Abdullah et al. (1991) and Yusuf et al. (1998) the general discussion of Jamee language revolves around phonology, morphology, and syntax in the language. In phonology, the study which is concerned with the sounds of words, the vowel and consonant system in Jamee language is explained. Abdullah et al. (1991) said that there are five vowels in Jamee language, i.e. /a/, /i/, /u/, /e/, and /o/. However, Yusuf et al. (1998) added two more vowels to this list, making a total of seven vowels, namely /i/, /e/, /a/, /o/, /u/, / /, and $/ \varepsilon /$. These additions perhaps may indicate that there was a change in the language during those years (from 1991 to 1998). It indirectly implies that Jamee is dynamic and exceptionally open to changes. Therefore, further research on their vowel system is deemed worthwhile.

Accordingly, in this study, the researcher focuses on analyzing the vowel production by the speakers in the Samadua district especially of the monophthong through acoustic analysis by using Praat Software. This kind of research has never been done on this language before. The previous studies focused on the auditory analysis of these vowels, without specific measuring tools to approximately measure the qualities of the vowels. Meanwhile, this study tries to make a breakthrough by focusing more on the scientific approach of acoustic analysis, making it a gap for this present research. We intend to answer the following research question: "What are the characteristics of monophthong vowels from the Samadua dialect of the Jamee language?" This research is expected to add knowledge to the existing literature of the languages spoken in Aceh province, specifically, to give information about the characteristic of monophthong vowels of the Jamee language. It also serves as documentation of the cultural heritage of the Acehnese people.

\section{Acoustic phonetics}

Phonetics is a systematic study of the sounds of speech, which is physically and directly observable
(Ladefoged, 2001; Ogden, 2009). It is not concerned with the meaning of these sounds, the order in which they are placed, or any other factor outside, but it is on how they are produced and heard and their various properties. Phonetics measure the physical attributes of speech sounds such as describing precisely how the mouth produces certain sounds, and the characteristics of the resulting sound waves (Fromkin et al., 2003).

Moreover, articulatory phonetics is the study of how phones are produced by the various organs in the mouth, throat, and nose and how they modify the airflow from the lungs (Ladefoged, 2001); it is how sounds are produced by the human vocal apparatus. Meanwhile, acoustic phonetics is the waves involved in speech sound and how they are interpreted by the human ear.

Acoustics is the branch of physics in the study of voice (which one characterized the mechanical waves such as in gases, liquids, and the soil); it is concerned with the production, control, transmission, reception, and sound (Weiss, 2008). It aims to describe and measure the properties of sounds supported by various waves related models (Tiwari, 2012). Acoustic phonetics is the physical focus on the characteristics of speech sounds transmitted between the mouth and ear.

In acoustic phonetics, acoustic analysis is a tool that concerns the distribution of speech sound by acoustic spectra such as frequency, intensity, and time. The acoustic analysis is used to analyze sound spectrograph that functions to draw spectra. The information is gained by presenting it in the form of a visible pattern of the passage of time shown on a horizontal scale in the spectrograph. The frequency, however, is presented in a vertical scale where the sound intensity with frequency and time appearing in a dark line (Fry, 2009). Nowadays, acoustics analysis is one of the methods used in phonetic studies (Boersma, 2013). It is the technique to construct stimuli for experiments. The analysis of acoustic signals is mainly performed with the help of generally available software, and among them is Praat, released by Paul Boersma and David Weenink in 1991.

\section{Vowels}

In the production of vowels, the vocal tract is more open compared to consonants (Rogers, 2000). According to McMahon (2002), articulatory qualities of vowels are frontness, tongue height, roundness, and tenseness. Frontness is the vowel produced with the front of the tongue raised and relatively in front. In English, the front vowels are /i/, /I/, /e/, /ع/ and /æ/. Moreover, tongue height is the vowel positioned based on the height of the tongue in the mouth. In English the vowels are /I/, $/ \mathrm{i} /, \mathrm{u} / \mathrm{and} / \mathrm{\sigma} /$. The rounded vowels are vowels in which the lips are relatively rounded when they are produced. In English, they are $/ \mathrm{u} /, / \mho /, / \mathrm{o} /$ and $/ \mathrm{o} /$. 
Furthermore, tenseness is vocal musculature. In English, they are /i/, /e/, /u/, /o/, and /o/.

Vowels are divided into two classes, namely monophthong, and diphthong. A monophthong is a single vowel that is not changed during its articulation (Almurashi, 2016), whereas a diphthong is when two vowels glide together and produced as one (McMahon, 2002). Besides, a diphthong consists of two components; the tongue changes position to produce the sound of two vowels (McMahon, 2002). The example of monophthong vowels in English is in words of 'top' /top/, 'get' /get/, and 'ship' / Jip/. Meanwhile, diphthong vowels in English are such as 'mouth' /mavo/, 'choice' /ffors/, and 'goat' /goot/ (Rogers, 2000).

\section{Jamee language}

Jamee language is similar to Minangkabau, spoken in West Sumatra, Indonesia, however, both languages have differences in dialect. Dialectal differences between Jamee and Minangkabau are likely influenced by assimilation factors with the Acehnese language which is predominantly spoken in Aceh Province (Isas, 1990). Research by Yunisaridewi (2014) found that despite many similarities, there are also vocabulary differences in the class of words verbs (20 words), nouns (20 words), adjectives (27 words), and numerals (7 words) between Jamee and Minangkabau. Among the examples is wa ang which refers to 'you', which is harsh in Minangkabau but subtle in Jamee. Besides, there are also some words from the Minangkabau that are shortened, such as the word wa ang in Minangkabau and becomes ang in Jamee (Isas, 1990).

According to Umar (2000), the Jamee language was originally brought by Minang society to South Aceh. Besides, Abdullah et al. (1991) inform that the Jamee language is a language used by the speakers of South Aceh Regency, Southwest Aceh Regency, and West Aceh. In South Aceh, Jamee is used by speakers in 16 districts such as Labuhan Haji, West Labuhan Haji, East Labuhan Haji, Meukek, Sawang, Pasie Raja, Central Kluet, South Kluet, East Kluet, North Kluet, East Bakongan, Bakogan, East Trumon, Trumon, Tapaktuan, and Samadua districts. Based on the research by Yusuf et al. (1998), there are several dialects of the Jamee language: Samadua (Samadua district), Tapaktuan (Tapaktuan district), Meureubo (some parts of West Aceh regency), and Susoh (some parts of Southwest Aceh regency). Nevertheless, in this study, we focus on the Samadua dialect, which is spoken in the Samadua district. The Samadua district can be seen on the map in Figure 1.

Based on the map in Figure 1, it can be seen that the position of Samadua district is near the capital city of South Aceh, which is Tapaktuan. However, compared to Jamee that is spoken in other districts, Abdullah et al. (1991) claim that Jamee spoken by the Samadua speakers have the least influence of other languages spoken in their areas, such as Acehnese and Indonesian.

\section{Figure 1}

Map of South Aceh District (Source Adapted from Google Map); Samadua is the area in grey

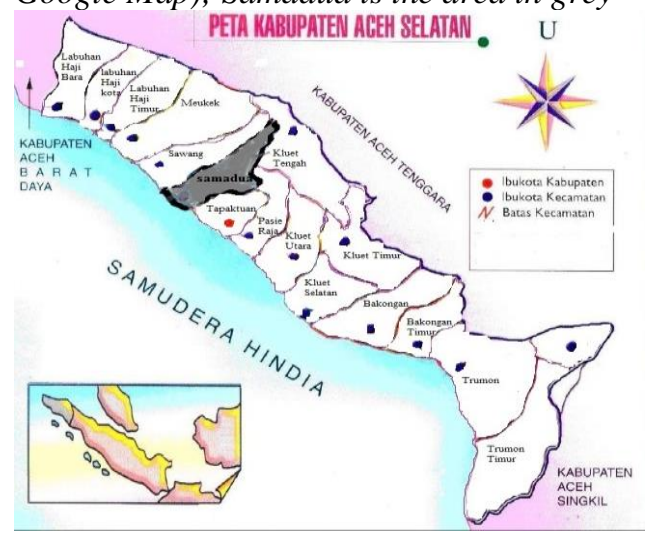

\section{Jamee vowels}

Not much research has been conducted on the Jamee vowels. Thus far, only two research studies have discussed the vowels of the language. The first research on the Jamee language was conducted by Abdullah et al. (1991). Employing a descriptive design, the study involved nine speakers of South Aceh, South West Aceh, and West Aceh. It describes the phonology, morphology, and syntax of the language. The data were obtained by conducting interviews, recording, and translation. The results show that the monophthong vowels of Jamee are /i/, /e/, /a/, /u/ and /o/. While the vowels of /ie/, /ai/, /ae/, /ao/, /au/, /ou/, /ui/ and /ue/ are the diphthongs, and the sounds of /p/, /b/, /t/,/d/, /k/, /g/, /j/, /tj/, /dj/ /s/, $/ \mathrm{h} /, / \mathrm{l} /, / \mathrm{m} /, / \mathrm{nj} /, / \mathrm{w} /$, and $/ \mathrm{r} / \mathrm{l}$ are the consonants. Figure 2 shows the positions of the vowels in the vowel space as depicted by Abdullah et al. (1991).

\section{Figure 2}

The Vowels of the Jamee Language (Abdullah et al., 1991)

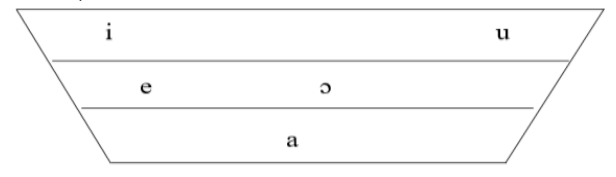

Seven years later, another study of the Jamee language was also conducted by Yusuf et al. (1998). The goal of this study was to describe the structure of the Jamee language in phonology, morphology, and syntax. This study was designed using a qualitative approach. The sample of this study was native speakers of Susoh, Lahuhan Haji Samadua, and Tapaktuan. The amount of the sample was eight persons. Phonologically, this study focused on vowels and consonants. Thus, it was found that there were seven monophthongs and six diphthongs 
in Jamee Language. These monophthongs are /a/, /i/, /u/, /e/, /o/, / //, and / $/$ /. Meanwhile, the diphthongs included /ai/, /ie/, /au/, /ui, /ue/ and /ee/. The consonants found in this language are $/ \mathrm{b} /, / \mathrm{c} /, / \mathrm{d} /$, /g/, /h/, /j/, /k/, /l/, /m/, /n/, /p/, /r/, /s/, /t/, /dh/ and /br/. The vowels as displayed by Yusuf et al. (1998) can be seen in Table 1 .

\section{Table 1}

The Classification of Jamee Vowel (Yusuf et al., 1998)

\begin{tabular}{lcccc}
\hline & $\begin{array}{c}\text { Front } \\
\text { Unrounded }\end{array}$ & $\begin{array}{c}\text { Central } \\
\text { Unrounded }\end{array}$ & $\begin{array}{c}\text { Back } \\
\text { Rounded }\end{array}$ & Neutral \\
\hline High & $\mathrm{i}$ & & $\mathrm{u}$ & $\begin{array}{c}\text { Close } \\
\text { Medium }\end{array}$ \\
$\mathrm{e}, \varepsilon$ & & 0,2 & $\begin{array}{c}\text { Mid Close } \\
\text { Open }\end{array}$ \\
Low & $\mathrm{a}$ & & & \\
\hline
\end{tabular}

The vowels of the Jamee language based on the contour of the mouth are classified into three types, namely round vowel, unrounded vowel, and neutral vowel. The rounded vowels are vowels that are uttered with rounded lips, for example, /o/, /u/, and $/ \mathrm{J} /$. The unrounded vowels are vowels that are uttered with unrounded lips, such as /i/, /e/, / $/ \varepsilon /$, and /a/. The neutral vowels are vowels uttered with the lips in a neutral position or spread, for instance, /a/ (Yusuf et al., 1998).

The differences between the two studies are that Yusuf et al. (1998) found seven monophthong vowels, meanwhile, Abdullah et al. (1991) found only five vowels. Furthermore, Yusuf et al. (1998) found six diphthongs vowels, but Abdullah et al., (1991) had found eight vowels. Additionally, both studies found the same number of consonants in the Jamee language. The inconsistencies in the number of vowels can be due to various reasons. First of all, the locations of both studies are in different villages even though they are all located in West Aceh. Second, the gender of the informants might have also influenced the differences; unfortunately, both studies did not specify the gender of the informants. Finally, the years the research conducted might also play a role in achieving different results. This is because language is dynamic, and its vibrant use by the speakers and their acceptance towards changes in their language could have also caused the differences. Jalaluddin et al. (2019) also assert that non-linguistic information such as topography, migration, history, and socio-culture serve as arguments for the distribution of dialects in one area.

\section{METHOD}

The method of this study is qualitative, where the researchers are a situated activity that locates the observer in the world (Creswell, 2003). This study was conducted at the Samadua district located in South Aceh. This location was chosen because it is considered as one of the districts with a greater number of Jamee language speakers compared to other districts in South Aceh.

\section{Informants}

The subjects of this study are native speakers of Jamee in the Samadua district. The researcher recorded ten female speakers. Females are chosen because males and females have different vocal tracts which lead to different sound production; females' formant frequencies are roughly $10 \%$ to $15 \%$ higher than males and thus produce clearer speech (Simpson, 2009; Wang \& van Heuven, 2006). They were also chosen based on their consent and availability to participate in this study. Their ages ranged from 45-50 years old. They also fulfilled the following criteria: they have never left the village to live in other places, except for visits and holidays, they are proud of their mother tongue and they are in healthy oral conditions (i.e., no cleft lips, no missing teeth, no cough or flu during the recording).

\section{Data collection}

Data were collected by using a word list (elicited speech) as suggested by Yusuf and Pillai (2013). The rationale of the word list is to have control over the phonetic environment of the monophthong vowels being investigated (King, 2006). The use of it also made it easier to analyze the vowel on the spectrogram and in the waveform (Hubais \& Pillai, 2010). Every respondent was to say each word in the word list by using a 'carrier sentence' (Feng, 2009; Hubais \& Pillai, 2010; van Leussen et al., 2011) in Jamee language, that is kecek iko sakali lai 'say the target word one more time', and each target word in the carrier sentence was repeated three times. The elicited speech of every respondent was recorded directly into Praat software on the laptop.

Before the word lists were made, the researchers had initially interviewed them to look for possible vowels that currently exist in the Jamee language. Seeing that previous studies proposed different numbers of monophthong vowels for this language, therefore these informal interviews with the ten female speakers were deemed important. They were asked to tell a story of their daily activity, folklore that existed in their culture, cultures that are still practiced by the society, how to cook traditional meals, and even sing traditional songs. They were free to choose among these topics. From these interviews, we selected target words from possible vowels that are used in the Jamee language. Consequently, the target words in the Jamee language selected for the word list are shown in Table 2. These words are common words that are still used by the Jamee speakers until today. The number of vowels found is different from Abdullah et al. (1991) but similar to Yusuf et al. (1998) with seven oral monophthong vowels. 
Table 2

\begin{tabular}{ccc} 
Wordlist & & \\
\hline Vowels & Jamee Words & English \\
\hline $\mathrm{a}$ & gado & throw \\
$\mathrm{u}$ & kudo & horse \\
$\mathrm{i}$ & kito & we \\
$\mathrm{e}$ & teko & kettle \\
$\mathrm{o}$ & doto & doctor \\
$\supset$ & toko & store \\
$\varepsilon$ & beko & later \\
\hline
\end{tabular}

As shown in Table 2, the target vowels are within the stop consonant environment as suggested by King (2006). These environments provide clear formants of the target vowel since they have very minimal effects on the vowel frequencies in Praat software (Yusuf \& Pillai, 2016). The speech of every respondent in Praat software was recorded at $44100 \mathrm{~Hz}$, then they were saved in the WAV file and annotated to the text grid for further analysis.

The recording was done in a quiet room in one of the houses in the village. All electronic devices (AC, fan, cell phone, fridge, etc.) were turned off during recording. The doors and windows were also closed to maintain the quietness: This is done to avoid Praat from picking up other noises except the respondent's voices only during recording. Each recording lasted 10 minutes for every respondent.

\section{Data analysis}

The result of the recording was analyzed through Praat software in spectrograms. The F1 (first formant) and F2 (second formant) of each vowel in the target word are measured at the midpoint of the vowel (Pillai \& Yusuf, 2012); this is because the characteristic of a monophthong does not change over its duration of production (Ladefoged, 2003). Moreover, F1 and F2 are considered adequate to illustrate the quality of monophthongs (Hossain et al., 2007; Jacobi, 2009; Misnadin, 2020) because higher formants (i.e., F3, F4, F5) are known to have less energy and thus provide less effective phonetic information than the lower formants (Hossain et al., 2007). F1 is related to vowel height, while F2 is related to the expression of the front/back dimensions (Jacobi, 2009; Watt \& Tillotson, 2001).

The researchers had also used manual eye checking on the formants because in some cases, the Linear Predictive Coding (LPC) analysis overlaid on digital spectrograms was not clear. Then the measurements in Hertz were transferred into Excel. In Excel, further calculations were done. First was converting Hertz to Bark by using the following formula (Deterding, 1997):

\section{$\mathrm{Hz}$ to $\mathrm{Bark}=13 * \mathrm{ATAN}(0.00076 * \mathrm{D} 2)+3.5 * \mathrm{ATAN}$ $((\mathrm{D} 2 / 7500) *(\mathrm{D} 2 / 7500))$}

*D refers to the column in Excel of the F1 or F2 measurement in Hertz.

The Bark scale is the underpinning of designing filter banks for the analysis of auditory signals such as speech (Stevens, 2000). The basis is on the human auditory system that comprises 24 critical band filters located in an intersection from low to high frequencies (Zwicker \& Terhardt, 1980). Finally, the average values were plotted on an F1-F2 chart. These charts provide a compelling scientific description of the vowels produced by speakers of a language (Ladefoged, 2003). Watt and Tillotson (2001) also inform that these formant plots offer an approximate representation of the vowel qualities

\section{FINDINGS AND DISCUSSION}

The average formant frequencies for the F1 and F2 of each vowel produced in the Samadua dialect of the Jamee language informants are shown in Table 3. Meanwhile, Figure 3 shows the plot of formant average values for the Samadua dialect monophthongs.

Figure 3 shows that the positions of $/ \mathrm{i} /, / \mathrm{e} /, / \varepsilon /$, $/ \mathrm{a} /, / \mathrm{u} /, / \mathrm{o} /$, and $/ \mathrm{o} /$, in general, are similar to the descriptions of vowels by Yusuf et al. (1998), who also discovered seven vowels in the Jamee language. However, this study has provided the approximate measurements of the vowels based on their F1 and F2 from the spectrograms in Praat. Figure 3 further displays that the vowels /i/, /e/ and $\mid \varepsilon /$ are indeed front vowels. Meanwhile, /a/ is an open, low, and central vowel. Finally, /o/, /u/, and / $/$ are back vowels. Furthermore, each quality of the vowel in the vowel space based on their measurements are described in the following subsections.

Table 3

F1 and F2 Average Values, and SD (in brackets) for the Jamee Language Monophthongs

\begin{tabular}{ccrrrrr}
\hline Vowel & Target & Ave. Duration & Ave. F1 (Hz) & Ave. F2 (Hz) & Ave. F1 (Bark) & Ave. F2 (Bark) \\
& word & \multicolumn{1}{c}{$(\mathbf{S e c})$} & & & & \\
\hline i & kito & $0,267(0,102)$ & $463(49,46)$ & $2484(164,72)$ & $4,41(0,44)$ & $14,45(0,41)$ \\
e & teko & $0,259(0,0978)$ & $550(32,91)$ & $2493(225,12)$ & $5,16(0,28)$ & $0,259(0,59)$ \\
$\varepsilon$ & beko & $0,204(0,101)$ & $641(46,24)$ & $2412(166,76)$ & $5,90(0,37)$ & $14,27(0,43)$ \\
u & kudo & $0,329(0,12)$ & $489(10.34)$ & $1165(85,61)$ & $4,64(0,48)$ & $9,49(0,48)$ \\
o & doto & $0,236(23,15)$ & $535(23,15)$ & $1434(0,20)$ & $5,04(0,34)$ & $10,89(0,33)$ \\
o & toko & $0,255(0,110)$ & $713(65,94)$ & $1312(69,08)$ & $6,48(0,51)$ & $10,29(0,36)$ \\
a & gado & $0,310(0,157)$ & $887(66,98)$ & $1898(108,09)$ & $7,75(0,46)$ & $12,75(0.38)$ \\
\hline
\end{tabular}


Figure 3

The Plot of Formant Average Values for the Jamee Language Monophthongs

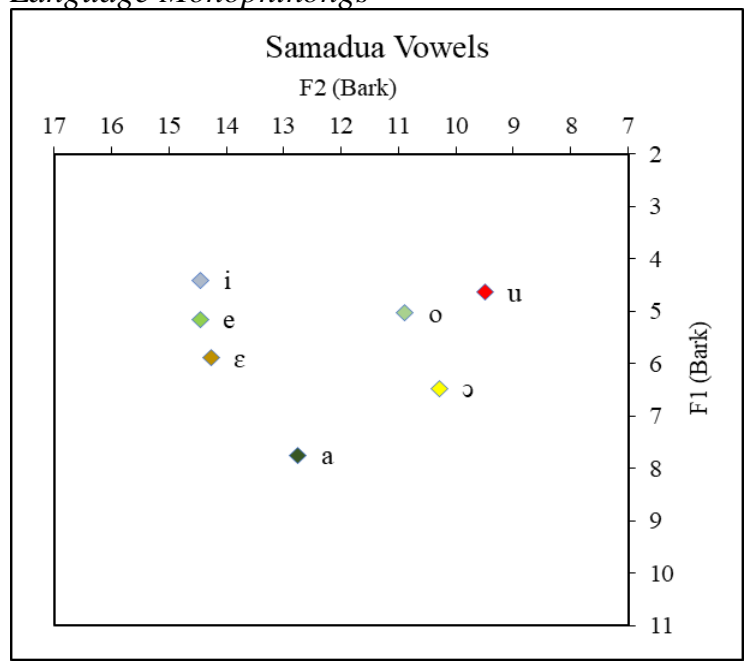

\section{The Production of /i/}

The scatter plot of /i/ as produced by the ten female speakers in Samadua is presented in Figure 4.

\section{Figure 4}

Vowel Plots of /i/for the Jamee Language Monophthong

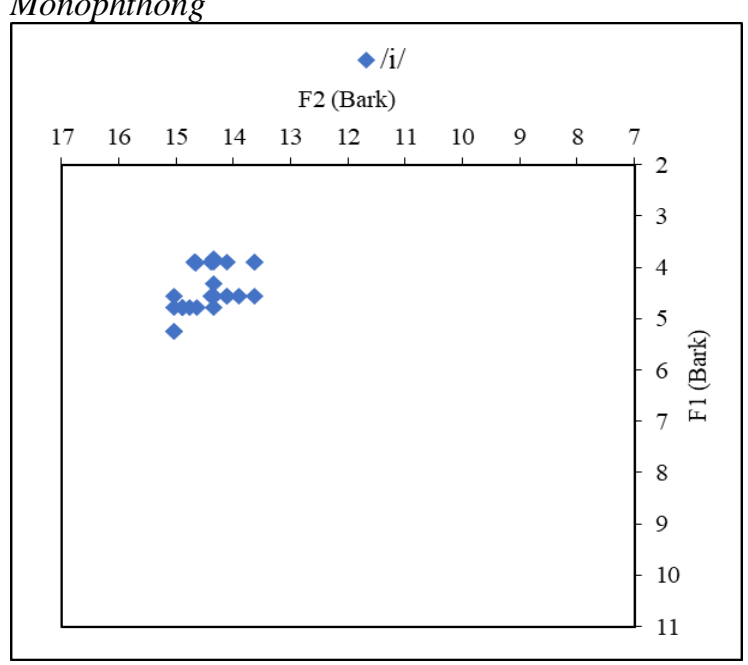

A total of 30 tokens of /i/ were extracted from the word kito 'we' in the wordlist. The position of the vowel /i/ of this dialect can be seen as the front high vowel. This result is similar to Abdullah et al. (1991) and Yusuf et al. (1998). They also described /i/ as a high front vowel in the Samadua dialect. Accordingly, this study finds the quality of /i/ with $\mathrm{F} 1=463 \mathrm{~Hz}$ and F2= $2484 \mathrm{~Hz}$.

\section{The Production of /e/}

The scatter plot of /e/ produced by ten female speakers in Samadua is presented in Figure 5.

\section{Figure 5}

Vowel Plots of /e/ for the Jamee Language Monophthong

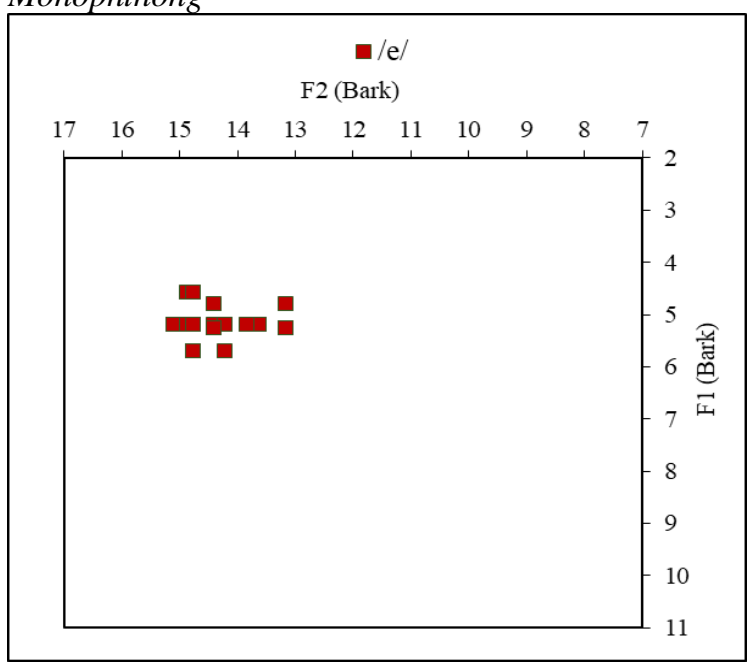

A total of 30 tokens of /e/ were extracted from the word teko 'kettle'. This result is similar to the studies by Abdullah et al. (1991) and Yusuf et al. (1998); they also described the vowel /e/ as a mid front vowel in the Jamee language. This study further measured the quality of /e/ that is with $\mathrm{F} 1=$ $550 \mathrm{~Hz}$ and $\mathrm{F} 2=2493 \mathrm{~Hz}$. T-tests were further conducted between the $\mathrm{F} 1$ and $\mathrm{F} 2$ average values of /i/ and /e/ to ensure that both are produced differently by the speakers. The results show that F1: $\mathrm{t}(58)=-7.97, \mathrm{p}<.0001$ and $\mathrm{F} 2: \mathrm{t}(58)=-0.19$, $\mathrm{p}=0.849$; meaning that since both are front vowels, there is no significant difference in their F1 average values but a significant difference in their F2 values (i.e., height). This further confirms that $/ \mathrm{i} /$ is produced higher than /e/ as displayed in Figure 3.

\section{The Production of $/ \varepsilon /$}

The scatter plot of $/ \varepsilon /$ produced by the ten female speakers in Samadua is presented in Figure 6.

A total of 30 tokens of $/ \varepsilon /$ were extracted from the word beko 'later'. This vowel is positioned in the low front vowel, and this result is similar to Yusuf et al. (1998). However, in the study by Abdullah et al. (1991), they did not include or did not find $/ \varepsilon /$ in the Jamee language vowel system. Nevertheless, this study has proven that this vowel is produced by the speakers today and the quality of $/ \varepsilon /$ is found to be $\mathrm{F} 1=641 \mathrm{~Hz}$ and $\mathrm{F} 2=2412 \mathrm{~Hz}$. Moreover, t-tests are conducted between the F1 and the F2 average values of $/ e /$ and $/ \varepsilon /$. The results show F1: $\mathrm{t}(58)=-8.8, \quad \mathrm{p}<.0001$ (i.e., significant difference) and $\mathrm{F} 2$ : $\mathrm{t}(58)=-1.59, \mathrm{p}=0.117$ (i.e., no significant difference). Again, the results confirm that $/ \mathrm{e} /$ and $/ \varepsilon /$ are both front vowels, in which /e/ is produced higher than $/ \varepsilon /$ as shown in Figure 3. 


\section{Figure 6}

Vowel Plots of $/ \varepsilon /$ for the Jamee Language Monophthong

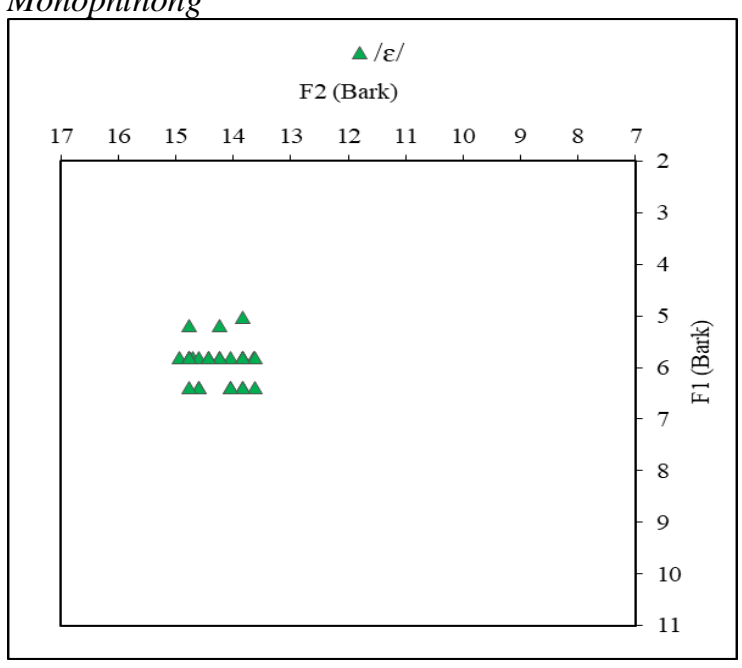

Based on the qualities of the front vowels, the scatter plot of $/ \mathrm{i} / \mathrm{h} / \mathrm{e} /$, and $/ \varepsilon /$ are vertical in the vowel space, as illustrated in Figure 7.

\section{Figure 7}

The Scatter Plot of the Front Vowels /i/, /e/ and / / / for the Jamee Language Monophthongs

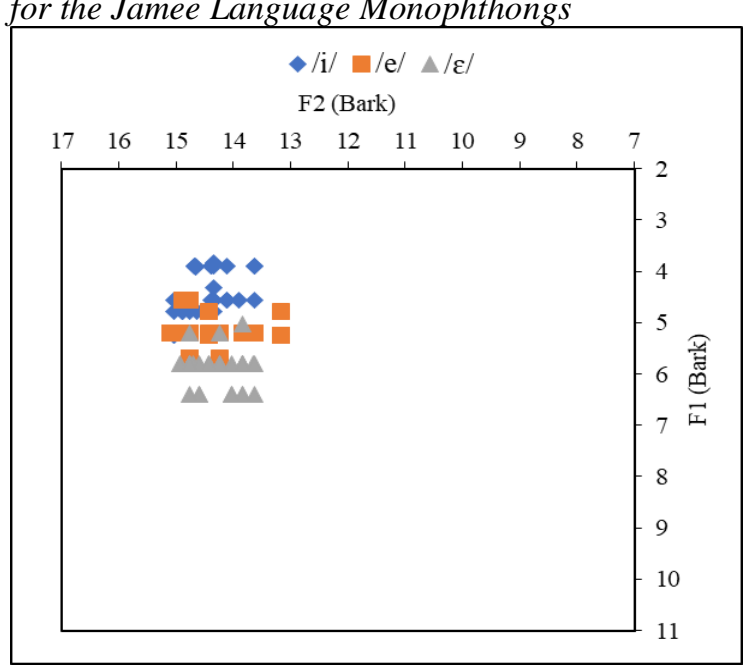

\section{The Production of $/ \mathbf{u} /$}

The scatter plot of $/ \mathrm{u} /$ produced by the ten female speakers in Samadua is presented in Figure 8.

A total of 30 tokens of $/ \mathrm{u} /$ were extracted from the word kudo 'horse'. The results showed that the vowel / $\mathrm{u} / \mathrm{d}$ of the Jamee language is a high back vowel. This study similar to the study by Yusuf et al. (1998), where they also found the position of vowel $/ \mathrm{u} /$ to be a high back vowel in this language. Moreover, the qualities of $/ \mathrm{u} /$ is found by the study to be $\mathrm{F} 1=489 \mathrm{~Hz}$ and $\mathrm{F} 2=1165 \mathrm{~Hz}$.

\section{Figure 8}

Vowel Plots of $/ u /$ for the Jamee Language Monophthong

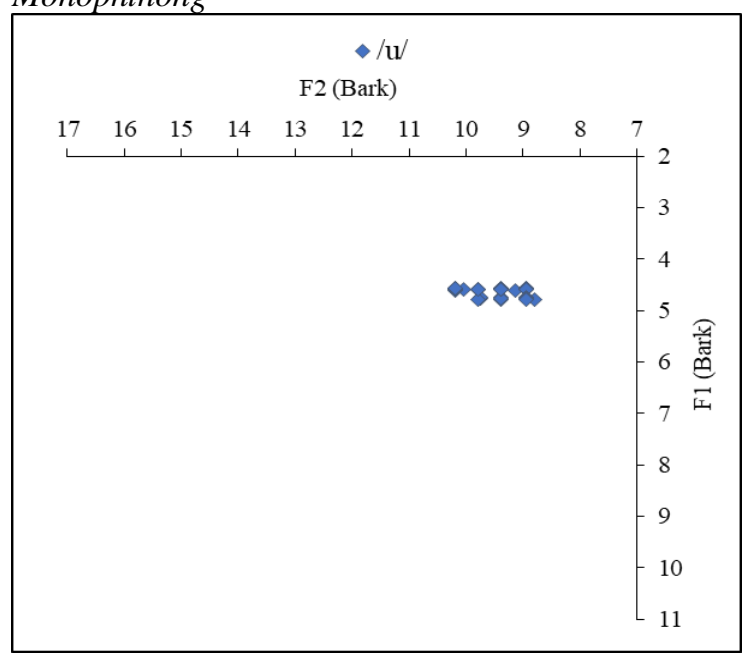

\section{The Production of /o/}

The scatter plot of /o/ produced by the ten female speakers in Samadua is presented in Figure 9.

\section{Figure 9}

Vowel Plots of Vowel /o/for the Jamee Language Monophthong

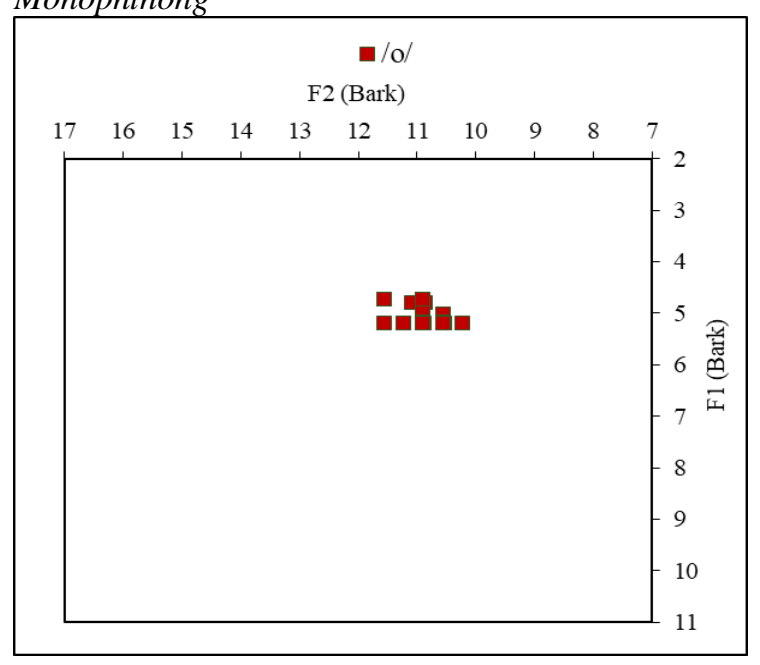

A total of 30 tokens of $/ 0 /$ were extracted from the word doto 'doctor'. The position of this vowel is seen as the mid back vowel, and this is similar to Yusuf et al. (1998). Hence, Abdullah et al. (1991) did not include /o/ in the Jamee language vowel system. This study has provided further evidence that this vowel is produced by these speakers. This study has found the quality of /o/ with $\mathrm{F} 1=535 \mathrm{~Hz}$ and $\mathrm{F} 2=1434 \mathrm{~Hz}$. T-tests were also conducted between the $\mathrm{F} 1$ and the $\mathrm{F} 2$ average values of $/ \mathrm{u} /$ and $/ \mathrm{o} /$, and the results showed that there are differences in their production, where $/ \mathrm{u} /$ is more fronted and higher than /o/ in the vowel space $(\mathrm{F} 1: \mathrm{t}(58)=-9.85$, $\mathrm{p}<.0001 ; \mathrm{F} 2: \mathrm{t}(58)=-13.09, \mathrm{p}<.0001)$. 


\section{The Production of $/ \mathrm{J} /$}

The scatter plot of $/ J /$ as produced by ten female speakers in Samadua is presented in Figure 10.

\section{Figure 10}

Vowel Plot of $/ \mathrm{J} /$ for the Jamee Language Monophthong

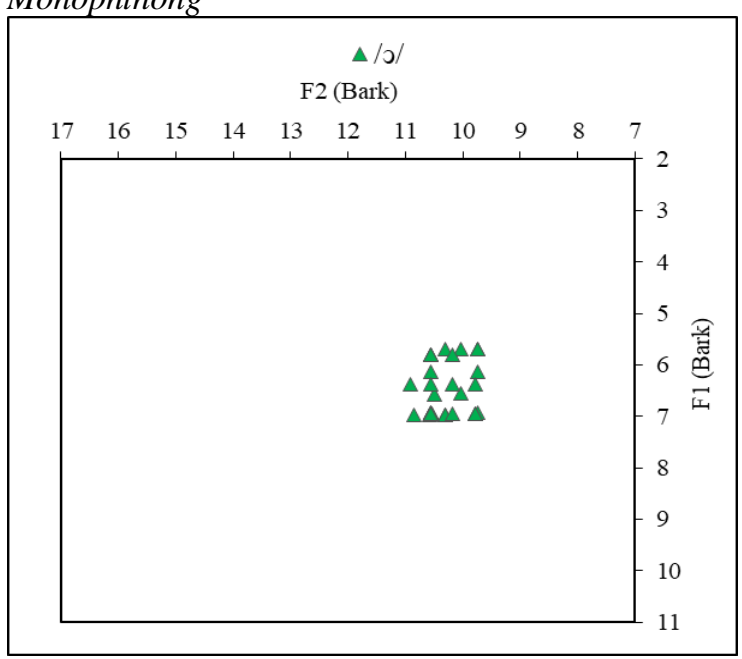

A total of 30 tokens of / / w were extracted from the word toko 'store' from ten female informants. This result is similar to the studies by Yusuf et al. (1998) where they also described the vowel /o/ in Jamee as a low back vowel. Meanwhile, Abdullah et al. (1991) displayed / $/$ / as a back vowel that is more fronted than $/ \mathrm{u} /$ in Samadua; it is even almost near to the central position in the vowel space (see Figure 2) and this is different from the finding of this study that describes it as a low back vowel (see Figure 3). This study further found that the quality of $/ \mathrm{J} /$ is with $\mathrm{F} 1=713 \mathrm{~Hz}$ and F2 $=1312 \mathrm{~Hz}$. T-tests were further conducted between the back vowels of $/ \mathrm{o} /$ and /o/ $(\mathrm{F} 1: \mathrm{t}(58)=-13.91, \quad \mathrm{p}<.0001 ; \quad \mathrm{F} 2$ : $\mathrm{t}(58)=+6.63, \mathrm{p}<.0001)$, and the results showed that they are produced differently, where /o/ is higher and more fronted than $/ \partial /$ in the vowel space as depicted in Figure 3.

Based on the qualities of vowels /o/, /J/, and $/ \mathrm{u} /$, they are back vowels, with $/ \mathrm{o} /$ and $/ \mathrm{J} /$ to be slightly to be more fronted than $/ u /$. This is illustrated in Figure 11. The front vowels of /i/, /e/ and $/ \varepsilon /$ (see Figure 7) are seen to be more vertically spread in the vowel space compared to the back vowels of /u/, /o/, /J/ (see Figure 11).

\section{The Production of /a/}

The scatter plots of /a/ produced by ten female speakers in Samadua are presented in Figure 12.

A total of 30 tokens of $/ \mathrm{a} /$ were extracted from the word gado 'throw'. The position of vowel /a/ of the Jamee language can be seen as the low central vowel. This result is the same as Abdullah et al. (1991) and Yusuf et al. (1998). They also described it as a low central vowel. Consequently, this study finds the quality of /a/ with $\mathrm{F} 1=887 \mathrm{~Hz}$ and $\mathrm{F} 2=$ $1898 \mathrm{~Hz}$.

\section{Figure 11}

The Scatter Plot of the Front Vowels /u/, /o/ and /J/ for the Jamee Language Monophthongs

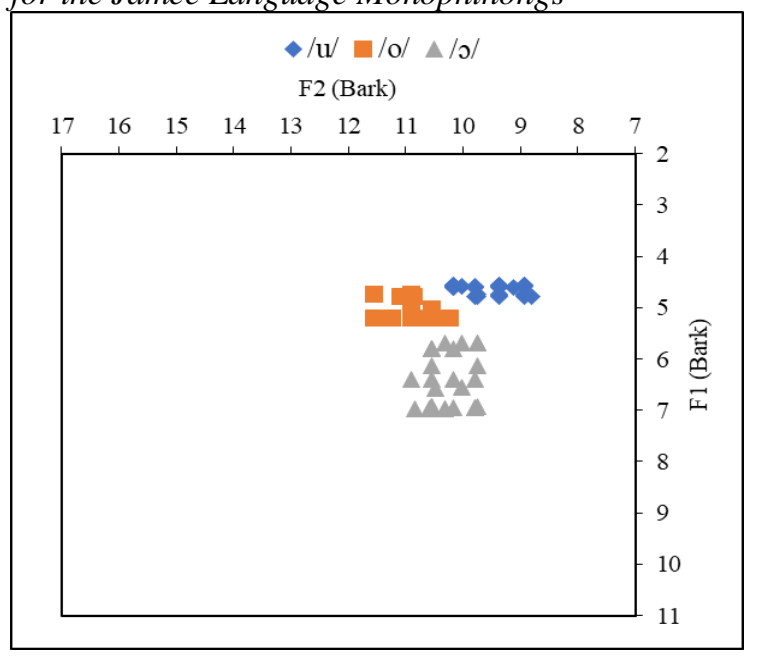

Figure 12

Vowel Plots of /a/ for the Jamee Language Monophthong

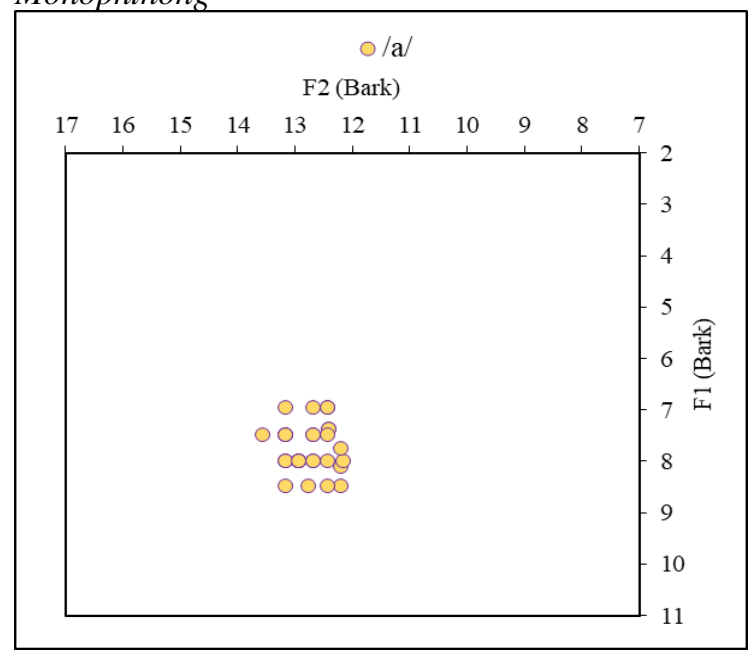

Looking at the production of the monophthong oral vowels investigated from the female speakers of Jamee language, the positions of $/ \mathrm{i} /, / \mathrm{e} /, / \varepsilon /, / \mathrm{a} /, / \mathrm{o} /$, $/ \mathrm{u} /, / \mathrm{J} /$ in the vowel space are similar to the seven vowels as described by Yusuf et al. (1998). The difference lies in the presentation of each of the vowel quality provided by this research based on the F1 and F2 from the spectrograms of each vowel in Praat. The front vowels are confirmed as /i/, /e/ and $/ \varepsilon /$, the central vowel is confirmed as $/ \mathrm{a} /$, and the back vowels are confirmed as /u/, and / / / are back vowels. Roach (2001, p. 39) further emphasizes the importance of studying the acoustic signal for language sounds because it "is completely observable: we can capture everything the listener hears in the form of a recording, and then measure whichever aspect of the signal that we want to 
know about". This observable method significantly contributes to the preservation and documentation of a language being studied. Consequently, the Jamee language spoken in Aceh was originated from Minangkabau, West Sumatra, but the two languages (i.e., Jamee and Minangkabau) are not completely the same due to regional assimilation (i.e., Jamee with Acehnese) (Abdullah et al., 1990). What is more, languages are constantly in change rather than static (Mufwene, 2003), which means that they are dynamic. As time passes, The Jamee language is expected to keep on evolving to adapt to diverse audiences and social contexts in their multiple speech communities that the speakers belong to. Hence, acoustic phonetics studies such as this research is a tool to provide an understanding of the nature of language variation and change (Baranowski, 2013).

\section{CONCLUSION}

This study found that the Jamee language has seven monophthong vowels, they are /i/, /e/, / / /, /a/, /o/, /u/ and $/ \mathrm{J} /$. The position of the vowels $/ \mathrm{i} / \mathrm{/} / \mathrm{e} / \mathrm{and} / \varepsilon /$ in the Jamee language are seen as front vowels, and $/ \mathrm{o} /, / \mathrm{u} /$ and $/ \mathrm{J} /$ as back vowels. Meanwhile, the vowel of /a/ is the only central vowel in this language. Furthermore, as a gap to previous studies, this acoustic study has calculated the approximate measurements for the vowels based on their F1 and F2 from the spectrograms in Praat. And so, the qualities of these vowels are /i/ with $\mathrm{F} 1=463 \mathrm{~Hz}$ and $\mathrm{F} 2=2484 \mathrm{~Hz}$, /e/ with $\mathrm{F} 1=550 \mathrm{~Hz}$ and $\mathrm{F} 2=$ $2493 \mathrm{~Hz}, / \varepsilon /$ with $\mathrm{F} 1=641 \mathrm{~Hz}$ and F2 $=2412 \mathrm{~Hz}$, /o/ with F1 $=535 \mathrm{~Hz}$ and F2 = $1434 \mathrm{~Hz}$, / / / with F1 $=713 \mathrm{~Hz}$ and F2 $=1312 \mathrm{~Hz}, / \mathrm{u} /$ with $\mathrm{F} 1=489 \mathrm{~Hz}$ and $\mathrm{F} 2=1165 \mathrm{~Hz}$, and finally /a/with $\mathrm{F} 1=887 \mathrm{~Hz}$ and F2 $=1898 \mathrm{~Hz}$. The findings of this study are seen important in the field of phonology, especially dialectology, as it assists linguists in preserving and documenting the language that is spoken by a minority in Aceh Province, Indonesia.

Nevertheless, this study was conducted not without limitations. The researchers recommend further studies to be conducted on the Jamee language vowels, such as to further explore the monophthongs from more words in Jamee (i.e., obtain from spontaneous speech such as interviews with the Jamee speakers) since this present study has a narrow word list used to represent the vowel phonemes. Moreover, diphthong and nasal vowels, and consonants, should also be explored through the acoustic approach. Future research should also consider measuring the qualities of the vowels and consonants as produced by the male speakers of the Jamee language. Additionally, there are many other languages spoken in Aceh and within these languages, varieties of dialects are also found. Other researchers are also encouraged to conduct similar studies on these different languages spoken in
Indonesia, especially in Aceh Province. To document, preserve, and maintain these languages are a part of enriching the Acehnese culture, especially in a country that is as super-diverse as Indonesia.

\section{ACKNOWLEDGEMENTS}

This research was assisted by a grant from Syiah Kuala University (Hibah Laboratorium Universitas Syiah Kuala 2016 for the Phonetics Laboratory). We thank Prof. Dr. Taufiq Saidi, Mr. Rahmad Dawood and Assoc. Prof. Dr. Taufik Fuadi Abidin for their support.

\section{REFERENCES}

Abdullah, W., Marlian, S., Rohana, S., \& Usman, B. (1991). Struktur bahasa Jamee [Structure of the Jamee language]. Departemen Pendidikan dan Kebudayaan.

Abdullah, W., Marlian, S., Rohana, S., \& Gade, M. H. (1990). Morfologi dan sintaksis bahasa Jamee [Morphology and Syntax of the Jamee Language]. Pusat dan Pengembangan Bahasa Departemen Pendidikan dan Kebudayaan.

Almurashi, W. A. (2016). Analysis and critical reflection of Acehnese language. International Journal of English Language and Linguistics Research, 4(2), 43-55.

Baranowski, M. (2013). Sociophonetics. In R. Bayley, R. Cameron, \& C. Lucas (Eds.), The Oxford handbook of sociolinguistics (pp. 3244). Oxford University Press.

Boersma, P. (2013). Acoustic analysis. In R. J. Podesva \& D. Sharma (Eds.), Research methods in linguistics (pp. 375-396). Cambridge University Press.

Creswell, J., W. (2002). Research design: Qualitative, quantitative, and mixed methods approaches. Sage Publication.

Deterding, D. (1997). The formants of monophthong vowels in Standard Southern British English pronunciation. Journal of the International Phonetic Association, 27, 47-55. https://doi.org/10.1017/S0025100300005417

Feng, L. (2009). A phonetic study of the vowel system in Suzhou Chinese [Unpublished doctoral dissertation]. University of Hong Kong.

Fromkin, V., Rodman, R., \& Hyams, N. (2003). An introduction to language. Wadsworth.

Fry, D. B. (2009). Acoustic phonetics: A course of basic readings. Cambridge University Press.

Hossain, S. A., Rahman, M. L. \& Ahmad, F. (2007). Acoustic classification of Bangla vowels. World Academy of Science, Engineering and Technology, 26, 321-326.

Hubais, A. \& Pillai, S. (2010). An instrumental analysis of English vowels produced by 
Omanis. Journal of Modern Languages, 20(1), 1-18.

Isas, B. (1990). Morfologi dan sintaksis bahasa Jamee [Morphology and syntax of Jamee language). Pusat Pembinaan dan Pengembangan Bahasa Departemen Pendldikan dan Kebudayaan.

Jacobi, I. (2009). On variation and change in diphthongs and long vowels of spoken Dutch [Unpublished doctoral dissertation]. University of Amsterdam.

King, P. (2006). An acoustic description of central vowels in three Austronesian languages of New Ireland. SIL Electronic Working Papers 2007, 1-21.

Jalaluddin, N. H., Tinggom, A. S., Hamzah, S. N., \& Lateh, H. (2019). Penyebaran dialek Melayu Satun di Langkawi dan di Thai: Satu kajian perbandingan berasaskan Geographic Information System (GIS). [The spread of Malay Satun dialect in Langkawi and in Thailand: A comparative study based on the Geographic Information System (GIS)]. GEMA Online ${ }^{\circledR}$ Journal of Language Studies, 19(1), 77-96. https://doi.org/10.17576/gema2019-1901-05

Ladefoged, P. (2001). A course in phonetics (4th ed.). Harcourt, Brace, Jovanovich.

Ladefoged, P. (2003). Phonetic data analysis: An introduction to fieldwork and instrumental techniques. Blackwell Publishing.

McMahon, A. (2002). An introduction to English phonology. Edinburgh University Press.

Misnadin, M. (2020). Phonetic realisations of Madurese vowels and their implications for the Madurese vowel system. Indonesian Journal of Applied Linguistics, 10(1), 173-183. https://doi.org/10.17509/ijal.v10i1.25033

Mufwene, S. (2003). Language endangerment: What have pride and prestige got to do with it? In B. Joseph (Ed.), When languages collide (pp. 324-346). Ohio State University Press.

Roach, P. (2001). Oxford introduction to language study: Phonetics. Oxford University Press.

Rogden, R. (2009). An introduction to English phonetics. Edinburgh University Press.

Pillai, S., \& Yusuf, Y. Q. (2012). An instrumental analysis of Acehnese oral vowels. Language and Linguistics, 13(6), 1029-1050.

Rogers, H. (2000). The sounds of language: An introduction to phonetics. Routledge.
Simpson, A. P. (2009). Phonetic differences between male and female speech. Language and Linguistics Compass, 3(2), 621-640. https://doi.org/10.1111/j.1749818X.2009.00125.x

Stevens, K. N. (2000). Acoustic phonetics. The MIT Press.

Tiwari, M. (2012). Speech acoustics: How much science? Journal of Natural Science, Biology and Medicine, 3(1), 24-31. https://doi.org/10.4103/0976-9668.95942

Umar, M. (2000). Dasar dan jiwa Aceh [The basics and soul of Aceh]. Yayasan Rusafat.

van Leussen, J. W., Williams, D., \& Escudero, P. (2011). Proceedings of the 17th International Congress of Phonetic Sciences (ICPhS XVII). City University of Hong Kong.

Wang, H., \& van Heuven, V. J. (2006). Acoustical analysis of English vowels produced by Chinese, Dutch and American speakers. Linguistics in the Netherlands, 23, 237-248. https://doi.org/10.1075/avt.23.23wan

Watt, D. \& Tillotson, J. (2001). A spectrographic analysis of vowel fronting in Bradford English. English World Wide, 22(2), 269-302. https://doi.org/10.1075/eww.22.2.05wat

Weiss, B. N. (2008). New research on acoustics. Nova Science Publishers, Inc.

Yunisaridewi, Y. (2014). Analisis perbandingan kosakata dalam Bahasa Jamee dan Minang [Unpublished master's thesis]. Universitas Syiah Kuala.

Yusuf, H., Mahmud, S., \& Ali, Z. (1998). Tata bahasa Jamee [Structure of the Jamee language]. Departemen Pendidikan dan Kebudayaan.

Yusuf, Q. Y., \& Pillai, S. (2012). Proceedings of UKM International Conference on Linguistics. Universiti Kebangsaan Malaysia.

Yusuf, Y. Q., \& Pillai, S. (2013). An acoustic description of diphthongs in two varieties of Acehnese. Pertanika Journal of Social Sciences \& Humanities, 21, 153-168.

Yusuf, Y. Q., \& Pillai, S. (2016). An instrumental study of oral vowels in the Kedah variety of Acehnese. Language Sciences, 54, 14-25. https://doi.org/10.1016/j.langsci.2015.09.001

Zwicker, E. \& Terhardt, E. (1980). Analytical expression for critical bandwidths as a function of frequency. The Journal of the Acoustical Society of America, 68, 1523-25. 